\title{
Participant Exposed to Secondhand Smoke
}

National Cancer Institute

\section{Source}

National Cancer Institute. Participant Exposed to Secondhand Smoke. NCI Thesaurus.

Code C156835.

The individual was exposed to secondhand smoke. 